Document downloaded from:

http://hdl.handle.net/10251/63313

This paper must be cited as:

Gasca-Tirado, J.; Manzano-Ramirez, A.; Vazquez-Landaverde, PA.; Herrera-Diaz, El.; Rodriguez-Ugarte, ME.; Rubio-Avalos, JC.; Amigó Borrás, V.... (2014). Ion-exchanged geopolymer for photocatalytic degradation of a volatile organic compound. Materials Letters. 134:222-224. doi:10.1016/j.matlet.2014.07.090.

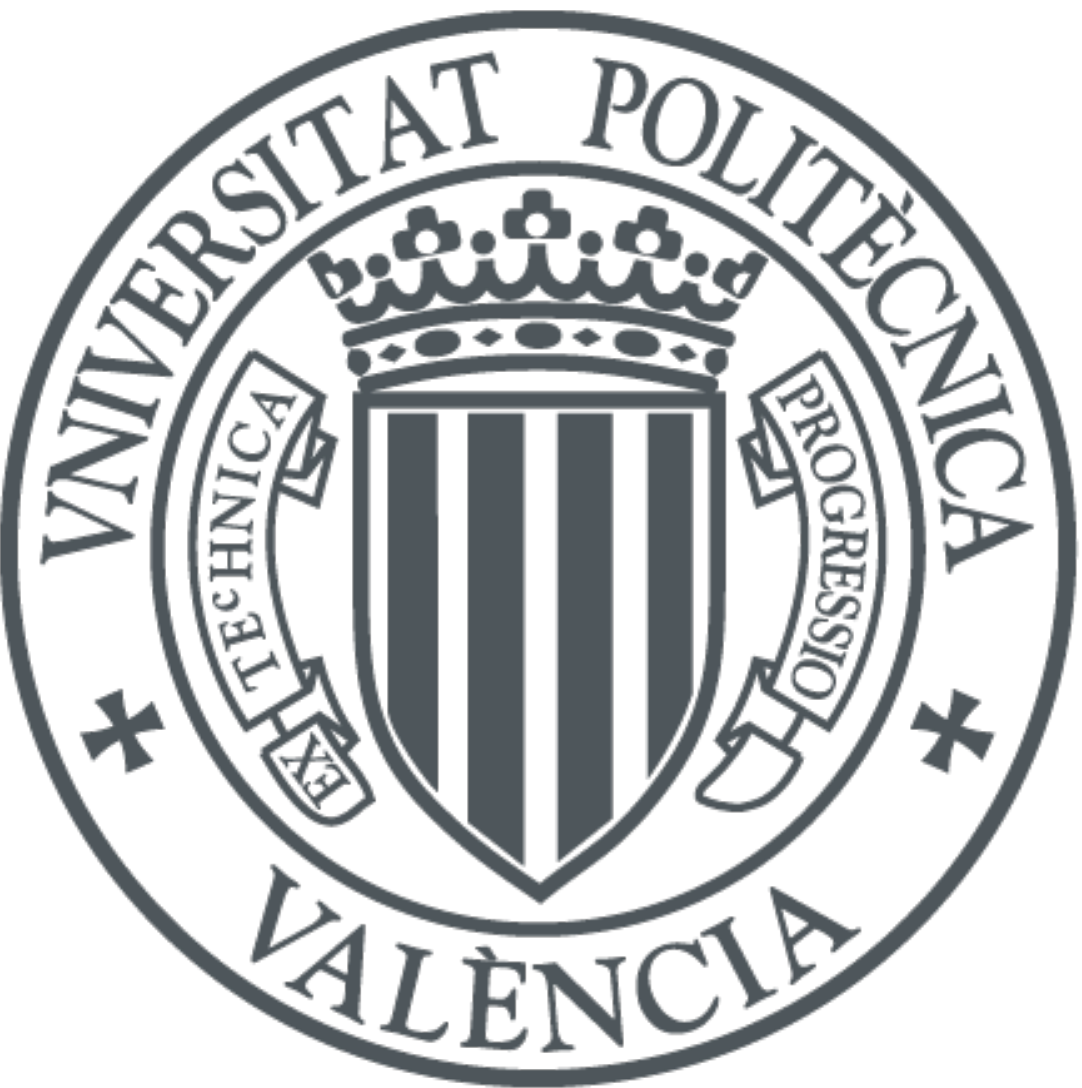

The final publication is available at

http://dx.doi.org/10.1016/j.matlet.2014.07.090

Copyright Elsevier

Additional Information 


\title{
Ion-exchanged geopolymer for photocatalytic degradation of a volatile organic compound
}

J.R. Gasca-Tirado a, A. Manzano-Ramírez b,n, P.A. Vazquez-Landaverde ${ }^{\text {c }}$, E.I. HerreraDíaz ${ }^{\mathrm{a}}$,

M.E. Rodríguez-Ugarte d, J.C. Rubio-Ávalos e, V. Amigó-Borrás f, M. Chávez-Páez g

a Universidad de Guanajuato. Campus Celaya-Salvatierra, Celaya, Guanajuato, C.P. 38110, Mexico

b CINVESTAV- I.P.N. Unidad Queretaro, Libramiento Norponiente No. 2000 , Fracc. Real de Juriquilla, Querétaro, Qro, C.P. 76230, Mexico

c Centro de Investigación en Ciencia Aplicada y Tecnología Avanzada del IPN Queretaro, Querétaro, C.P. 76090, Mexico

d Universidad Tecnológica de Queretaro, Queretaro, C.P. 76148, Mexico

e Faculty of Civil Engineering, Universidad Michoacana de San Nicolás de

Hidalgo, Morelia, Michoacán, C.P. 58000, México f Instituto de Tecnología de

Materiales, Universidad Politécnica de Valencia. Camino de Vera, s/n, C.P. 46022,

Valencia Spain g Instituto de Física. Universidad Autónoma de San Luis Potosí

\begin{abstract}
In the present work it is shown how geopolymers can be used to control indoor and outdoor air pollution by photolysis of 2-Butanone as a Volatile Organic Compound (VOC). An ion exchange procedure was followed to incorporate $\mathrm{TiO} 2$ into a geopolymer (IEG), and different 2-Butanone concentrations were used in a batch reactor under dry and humid conditions. Variation on 2-Butanone concentration was followed by gas chromatography. A Langmuir-Hinshelwood model was used to determine the disappearance rate of reactant at the initial stage of the reaction.
\end{abstract}

Keywords: Geopolymer, 2-butanone, Ion-exchange, VOC, Photolysis

1. Introduction

Geopolymers are environmental friendly materials with low energy consumption and reduced "greenhouse" emissions [1]. They are synthesized at low temperatures by chemical reaction between aluminosilicates and alkaline polisilicates [1]. Their applications are wide; including the immobilization of toxic and radioactive waste [2,3], support for catalytic materials [4,5] and adsorber for volatile organic compounds (VOC) as formaldehyde [6].

VOC's are human-made and naturally occurring chemical compounds that stand high on the list of the pollutants detected in indoor atmospheres [7,8]. Although their concentrations are not considered harmful to human health with indoor short-term exposure, they have become a major public concern since people usually spend over $70 \%$ 
of their time indoor [7-11]. Some of the symptoms that arise from a long term exposure are asthma, cardiovascular illnesses and mutagenic or carcinogenic effects described at the "sick building syndrome" [9].

These clinical manifestations can be reduced if the indoor air quality is improved. One way to achieve this is by photolysis, which is based on the use of a light activated semiconductor to speed up VOC oxidation, when the semiconductor is irradiated with photons of the appropriate wavelength (equal or higher than the band gap energy). Resultant electron-hole pair can oxidize directly the adsorbed-VOC or may give rise, in combination with other chemical substances, to the formation of highly reactive species to degrade them finally [12]. In this paper, it is shown how an ion-exchanged geopolymers (IEG) [5] can be used to reduce indoor and outdoor air pollution by photolysis of VOC's. Different 2-Butanone concentrations were studied in the batch reactor under dry and humid conditions and followed by gas chromatography. A Langmuir-Hinshelwood model $(\mathrm{L}-\mathrm{Hm})$ was used to determine the reaction progress at the initial stage of the reaction.

2. Materials and methods

Materials: Metakaolin was Metamax from BASF Corporation. Ammonium Titanyl Oxalate Monohydrate, Methanol, and 2-Butanone were from Sigma Aldrich. Sodium Hydroxide and Sodium Silicate were from SIDESA Mexico and the high purity $80 \%$ N2-20\% O2 gas mixture was from Infra, Mexico.

Ion-exchanged geopolymer synthesis: The geopolymers were treated with an aqueous solution of (NH4)2 $\mathrm{TiO}(\mathrm{C} 2 \mathrm{O} 4) 2 \cdot \mathrm{H} 2 \mathrm{O}$ (ammonium titanyl oxalate Monohydrate). Samples were dried to obtain geopolymer with a reactive surface of $170 \mathrm{~cm} 2(4 \sim 42.5 \mathrm{~cm} 2[5])$.

Characterization of the IEG: Specific surface (S), pore volume (V) and pore width (D) of the synthesized IEG were determined by nitrogen adsorption on a NOVA 2000e Quantachrome. Sample was taken from the synthesized IEG and desorpted for $24 \mathrm{~h}$ at $1201 \mathrm{C}$ to remove free water.

To assess nano- $\mathrm{TiO}_{2}$ on the geopolymer surface, $2.5 \mathrm{mg}$. of geopolymer was sampled and milled. To obtain the smallest and lightest particles, the sample was dispersed in methanol and stirred by $5 \mathrm{~min}$. After this time the solution was settled for $20 \mathrm{~min}$ and $100 \mu \mathrm{l}$ were collected from the solution (upper sur- face). Particles were set in a TEM sample support mesh and characterized with a JEM1010 JEOL TEM.

Photocatalytic reactor and procedure: A $12 \mathrm{~L}$ batch reactor was used for photocatalytic degradation of 2-butanone. In this, one UV lamp (Exo Terra $15 \mathrm{~W}, \lambda$ peak $1 / 4365 \mathrm{~nm}$ ) within a quartz tube, was at $9 \mathrm{~cm}$ away from the geopolymer surface.

First, the reactor was flushed out and filled with dry air ( $80 \% \mathrm{~N} 2-20 \% \mathrm{O} 2$ gas mixture) at normal temperature and pressure conditions (NTP). To obtain $30 \%$ relative humidity (RH), air was bubbled through a glass saturator containing deionized water. Wet bulb and dry temperatures were measured and once the humidity was fixed, the reactor inlet and outlet valves were closed to hold RH and NTP conditions inside the reactor.

2-butanone concentrations $(0.5$ to $5 \mathrm{~g}-3)$ were injected in the reactor through a pierceable septum placed on the head of the reactor. Before the lamp was turned on, the temperature was 
fixed at $251 \mathrm{C}$ and the system was allowed to reach steady state conditions (gas-solid adsorption equilibrium) for $24 \mathrm{~h}$.

Gas samples $(1 \mathrm{~mL})$ were extracted from the reactor and injected into a $7890 \mathrm{~A}$ gas chromatograph (Agilent Technologies Inc., Santa Clara, CA).

High purity Helium was used as carrier gas, at $1 \mathrm{~mL} / \mathrm{min}$. Chromatographic peaks were identified using a 5975C VL mass spectrometer (Agilent Technologies).

Langmuir-Hinshelwood: modelFor heterogeneous catalysis, the adsorption of chemical species over the catalyst is another factor that should be considered before any chemical reaction arise [13]. The $\mathrm{L}-\mathrm{Hm}$, (Eq. 1) can be used to determine the disappearance rate $(r)$ of reactant (2-Butanone) at the initial stage of the reaction [14].

$$
r_{0}=\frac{k K C_{0}}{1+K C_{0}}
$$

where ro is the initial reaction rate $\left(\mathrm{g} \mathrm{m}^{-3} \mathrm{~min}^{-1}\right), \mathrm{C}_{0}\left(\mathrm{~g} \mathrm{~m}^{-3} \mathrm{~min}^{-1}\right)$ the initial concentration, $\mathrm{k}$ is the reaction rate constant $\left(\mathrm{g} \mathrm{m}^{-3} \mathrm{~min}^{-1}\right)$ and $\mathrm{K}$ is the adsorption equilibrium constant $\left(\mathrm{g} \mathrm{m}^{-3}\right.$ $\mathrm{min}^{-1}$ ). If the experimental data fit to model (Eq. 1), chemical reaction is the limiting step in the Langmuir-Hinshelwood reaction mechanism. Otherwise, when the experimental data fits the L-Hm described by Eq. 2 (where $\mathrm{k}_{\mathrm{ads}}\left(\mathrm{min}^{-1}\right)$ is the adsorption constant) the adsorption of chemical species is the rate limiting step.

$$
C_{0}=k_{a d s} C_{0}
$$

In this study, initial reaction rates $\left(r_{o}\right)$ were calculated by modeling the kinetic slopes by first order polynomial and by deriving them at $t=0\left(r_{0}=\mathrm{d} C_{0} /\left.\mathrm{dt}\right|_{t=0}\right)$. The Langmuir-Hinshelwood reaction rate $k$ and the Langmuir adsorption constant $K$ were calculated by least square analysis of $r_{0}$ versus $C_{0}$.

\section{Results and discussion}

Table 1 shows the physical properties $S, V$ and $D$ of ion and non ion-exchanged geopolymers. The reduction in pore width and the increase in specific surface in comparison with a non ion- exchanged geopolymer settle that $\mathrm{TiO}_{2}$ particles growth inside the geopolymer [5]. $\mathrm{TiO}_{2}$ particles were set in small cluster of $10 \mathrm{~nm}$ in width as shown by TEM, Fig. 1.

Table 1 Specific surface $(S)$, pore volume $(V)$ and pore width $(D)$ of ion and non ionexchanged geopolymer.

\begin{tabular}{lccc}
\hline Sample & $S\left(\mathrm{~m}^{2} / \mathrm{g}\right)$ & $V\left(\mathrm{~cm}^{3} / \mathrm{g}\right)$ & $D(\mathrm{~nm})$ \\
\hline Geopolymer & 27.21 & 0.2076 & 30.52
\end{tabular}




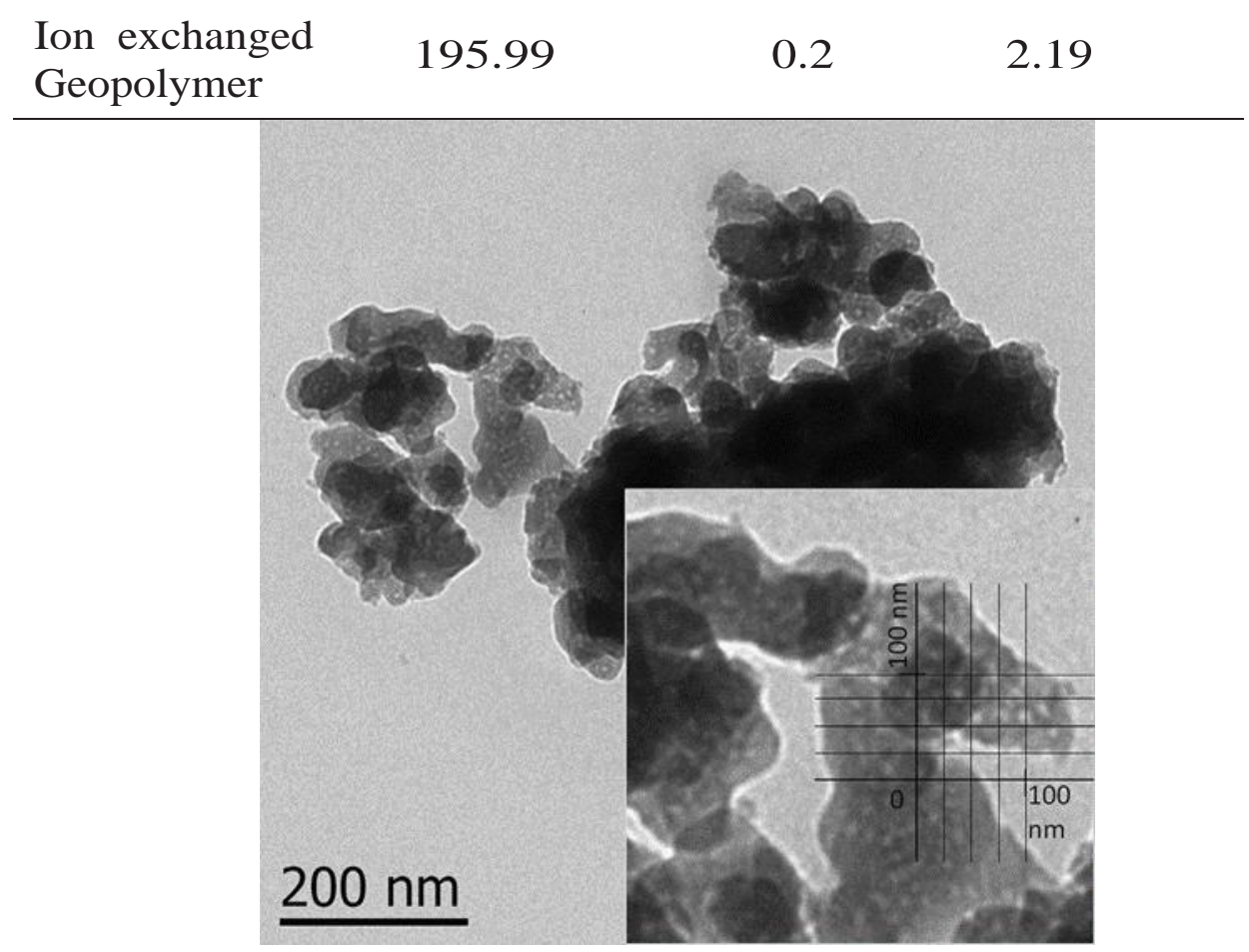

Fig. 1. TEM micrograph of the ion-exchanged geopolymer.

The IEG degrade the 2-butanone, the fraction conversion of 2-butanone and reaction products was followed by measuring their concentrations through time as it is observed on Fig. 2.

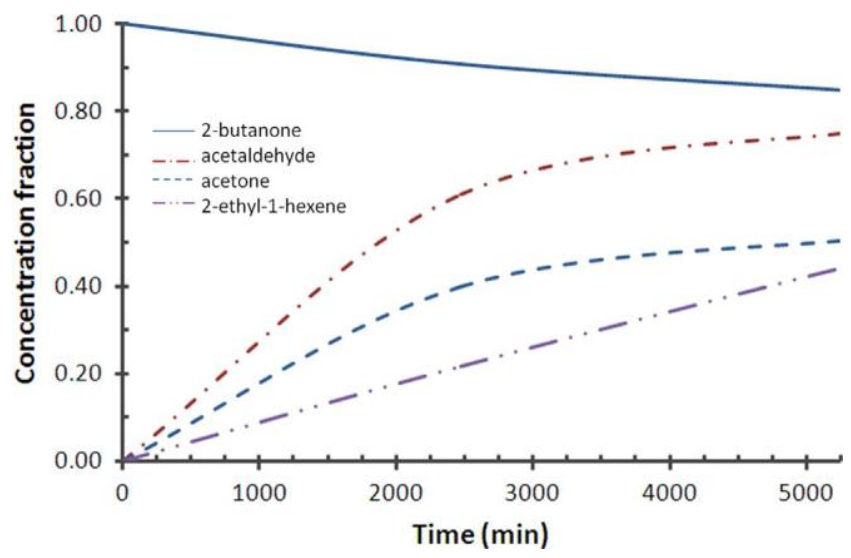

Fig. 2. Chromatographs of gas samples collected from the reactor: (A) before and (B) after $5 \mathrm{~h}$ of UV light exposure at $[2-\text { butanone }]_{\mathrm{o}}=4.97 \mathrm{~g}^{-3}$

Reaction products were acetaldehyde and acetone at retention times of 1.6 and $2.08 \mathrm{~min}$, respectively. Their concentration, area under the curve, increased just after UV light exposure as a consequence of the photolysis carried out by the IEG over 2-butanone (retention time at $2.8 \mathrm{~min}$.). These reaction products are in accordance to Vincent et al. 
for the degradation of 2-butanone by $\mathrm{TiO}_{2}$ (P25 Degussa) over a fiberglass support [6]. In addition, chromatograph exhibited the presence of 2-etil-1- hexene (retention time at 2.26 min) whose appearance has not been reported previously, and that could be formed by the linking of alkyl radicals.

The plotting of $r_{0}$ versus $C_{0}$ (Fig. 3) of all photolysis carried out under dry and humid conditions reported a linear correlation, that according to the Langmuir-Hinshelwood model correspond to an adsorption limiting step reaction (Eq. 2) at $\mathrm{TiO}_{2}$ active sites available for the adsorption/desorption of reactants and products, respectively. Nevertheless, the observed reaction rates under humid conditions were slower that in dry air, in spite of it is well known that water vapor reacts as hole trap $\left(\mathrm{h}^{+}\right)$to be transformed into more reactive hydroxyl radicals $\mathrm{OH}^{*}$. This could be ascribed to the competition between 2-butanone and water for the active sites on the IEG. This behavior is described by comparing the slopes the Langmuir-Hinshelwood plots at the initial reaction rates versus 2-butanone initial concentration under dry and humid conditions (Figs. 3A and B respectively).
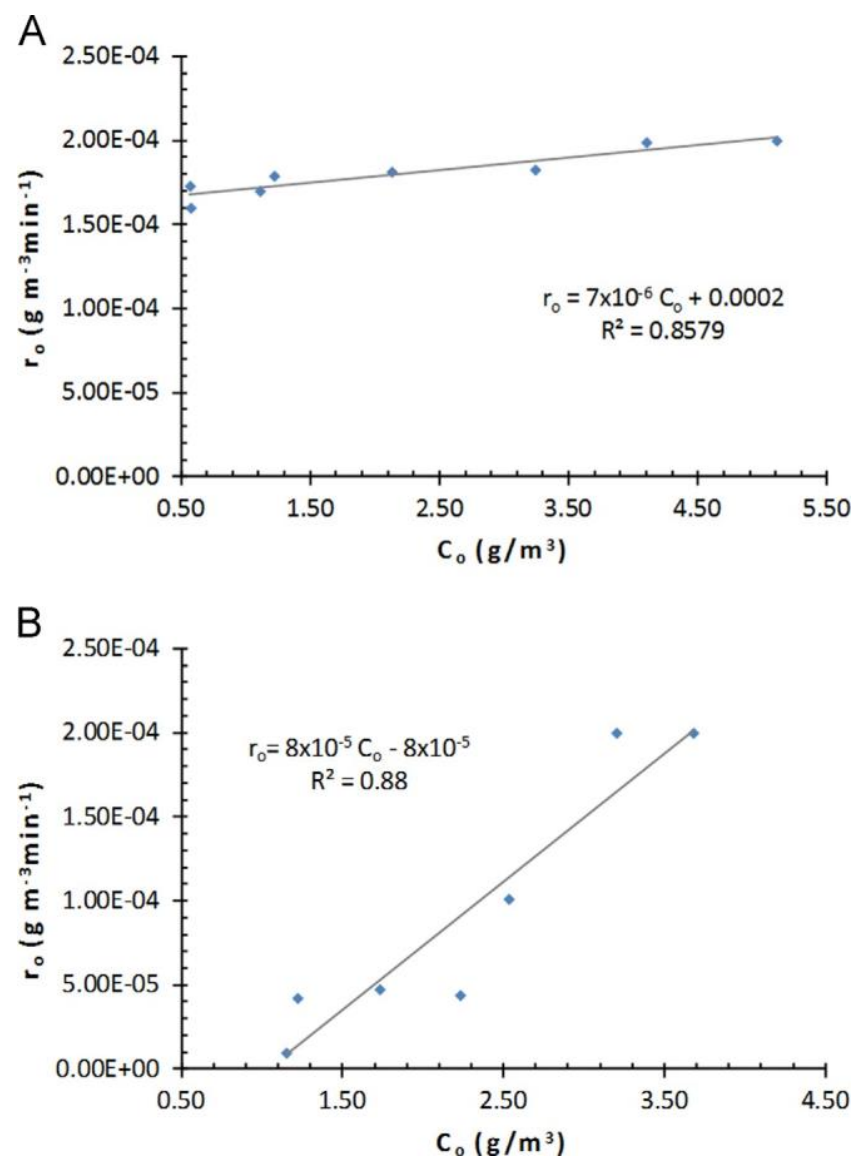

Fig. 3. Langmuir-Hinshelwood plots of the initial reaction rate $\left(r_{0}\right)$ versus 2-buta-none initial concentration $\left(C_{0}\right)$ under dry $(\mathrm{A})$ and humid air at $30 \% \mathrm{RH}$ (B).

Hence, the Langmuir-Hinshelwood plots of the initial reaction rate versus 2-butanone initial 
concentration (dry air and humid conditions) gave indication that reactant adsorption is the limiting step, Eq. 2. This chemical adsorption happens on the surface of the catalyst and it is an equilibrium process between the bulk fluid and the species adsorbed on the catalyst.

4. Conclusions

The incorporation of $\mathrm{TiO}_{2}$ into the geopolymer pores was confirmed by the changes in physical properties of IEG which was able to degrade 2-butanone at $\mathrm{TiO}_{2}$ active sites for the adsorption/desorption of reactants and products, respectively. Lamp intensity employed was enough and more efficient to achieve the photolysis, as compare to the used reported elsewhere [14,17-18]. The presence of 2-etil-1-hexene, not previously reported, suggest a possible linking reaction between radicals. Slower reaction rates at humid conditions are ascribed to the competition of 2-butanone with water molecules for the IEG active sites. Results showed that reactant adsorption is the limiting step.

Acknowledgments

The authors thank Lourdes Palma Tirado from UNAM, Miriam Rodriguez Olvera from CICATA for their technical support.

References

[1] Davidovits J. J Therm Anal 1991;37:1633-56.

[2] Xu H, Van Deventer JSJ. Int J Miner Process 2000;59:247-66.

[3] Fernandez-Jimenez A, Palomo A. Cem Concr Res 2005;35:1984-92.

[4] Sazama P, Bortnovsky O, Dedecek J, Tvaruzková Z, Sobalík Z. Catal Today 2011;164:92-9.

[5] Gasca-Tirado JR, Manzano-Ramírez A, Villaseñor-Mora C, Muñiz-Villarreal MS, Zaldívar-Cadena AA, Rubio-Ávalos JC, et al. Microporous Mesoporous Mater 2012;153:282-7.

[6] Huang Y, Han M. J Hazard Mater 2011;193:90-4.

[7] Salthammer T, Bednaerk M, Fuhrmann F, Funaki R, Tanabe SI. J Photochem Photobiol A 2002;152:1-9.

[8] Lee SC, Li WM, Ao CH. Atmos Environ 2002;36:225-37.

[9] United States Protection Agency. Air and Radiation (6609 J). Res Dev; 1991.

MD-56.

[10] Ongwandee M, Moonrinta R, Panyametheekul S, Tangbanluekal C, Morrison G. Build Environ 2011;46:1512-22.

[11] Dimosthenis A, Sarigiannis P, Spyros A, Karakitsios G, Ioannis Liakos L, Katsoyiannis A. Environ Int 2011;37:743-65.

[12] Kisch H. In: Serpone N, Pellizetti E, editors. Photocatalysis. Wiley; 1989. p. 1-8. [13] Zhao J, Yang X. Build Environ 2003;38:645-54.

[14] Raillard C, Hequet V, Le Cloirec P, Legrand J. J Photochem Photobiol A 2004;163:42531.

[17] Raillard C, Hequet V, Le Cloirec P, Legrand J. Appl Catal B-Environ 
2005;59:213-20.

[18] Arconada N, Castro Y, Duran A, Hequete V. Appl Catal B-Environ 2011;107:52-8. 